\title{
Model Regresi Spasial dan Aplikasinya dalam Menganalisis Angka Putus Sekolah Usia Wajib Belajar di Provinsi Sulawesi Selatan
}

\author{
Wahidah Sanusi ${ }^{1}$, Hisyam Ihsan ${ }^{1}$, dan Nur Hikmayanti Syam ${ }^{1, \text { a) }}$ \\ ${ }^{1}$ Jurusan Matematika, Fakultas Matematika dan Ilmu Pengetahuan Alam \\ Universitas Negeri Makassar \\ a) nurhikmayantisyam@yahoo.co.id
}

\begin{abstract}
Abstrak. Penduduk Sulawesi Selatan pada kelompok pengeluaran terendah menunjukkan bahwa banyak dari mereka mengalami putus sekolah. Salah satu faktor yang mempengaruhi angka putus sekolah yaitu lokasi antar wilayah. Tujuan penelitian ini adalah untuk mengaplikasikan regresi spasial untuk memodelkan angka putus sekolah di Provinsi Sulawesi Selatan. Pengujian dependensi spasial dan pemilihan model regresi spasial dilakukan menggunakan uji Moran's I dan Langrange Multiplier (LM). Dari hasil penelitian, kasus putus sekolah untuk tingkat SMP tidak memiliki dependensi spasial baik dalam lag maupun error dan berdasarkan model regresi klasiknya diperoleh variabel prediktor yang signifikan mempengaruhi variabel respon adalah jumlah penduduk miskin $\left(X_{3}\right)$. Sedangkan untuk kasus angka putus sekolah tingkat SMA, diperoleh dependensi spasial dalam error sehingga model regresi spasial yang digunakan adalah Spatial Error Model (SEM) dan matriks pembobotnya adalah queen contiguity. Matriks pembobot tersebut menggambarkan ukuran kedekatan antar wilayah pengamatan. Hasil analisis spasial menunjukkan bahwa variabel prediktor yang signifikan mempengaruhi variabel respon adalah jumlah penduduk miskin $\left(X_{3}\right)$ dan kepadatan penduduk $\left(X_{5}\right)$, dengan nilai $R^{2}=89,78 \%$ dan AIC $=430,604$.
\end{abstract}

Kata Kunci: Langrange Multiplier, Moran's I, Putus Sekolah, Regresi Spasial, Spatial Error Model (SEM).

\begin{abstract}
The population of South Sulawesi in the lowest expenditure group shows that many of them have dropped out of school. One of the factors that influence the drop out rate is location between regions. The purpose of this study was applying spatial regression to the model drop out rates in South Sulawesi Province. Spatial dependency test and spatial regression model selection were performed using Moran's I and Langrange Multiplier (LM) tests. From the results of the study, the drop out case for junior high school didn't have spatial dependencies either in lag or error and based on the classical regression model obtained predictor variable significantly affect the response variable was the number of poor people $\left(X_{3}\right)$. As for the case of high school drop out rate, obtained spatial dependency in error so that spatial regression model used was Spatial Error Model (SEM) and weighting matrix was queen contiguity. The weighted matrix represents the measure of proximity between observation areas. The result of spatial analysis indicates that the significant predictor variable influencing the response variable was the number of the poor $\left(X_{3}\right)$ and the population density $\left(X_{5}\right)$, with $R^{2}=89.78 \%$ and $A I C=430,604$.
\end{abstract}

Keywords: Lagrange Multiplier, Moran's I, School Drop Out, Spatial Regression, Spatial Error Model (SEM).

\section{PENDAHULUAN}

Analisis regresi adalah suatu metode yang digunakan untuk menganalisis hubungan antara variabel respon dengan beberapa variabel prediktor (Ruliana, 2015). Metode regresi adalah 
metode statistik untuk menduga parameter model yang terbentuk dengan menghubungkan respon dan prediktor (Drapper \& Smith, 1992). Metode ini mengasumsikan bahwa respon tidak dipengaruhi lokasi geografis. Namun, pada hukum pertama tentang geografi yang dikemukakan oleh Tobler yang menyatakan segala sesuatu saling berhubungan satu dengan yang lainnya, tetapi sesuatu yang dekat lebih mempunyai pengaruh daripada sesuatu yang jauh (Anselin, 1988).

Suatu analisis pemodelan regresi untuk mengetahui faktor-faktor yang mempengaruhi persentase suatu kejadian yang dipengaruhi oleh karakteristik wilayah sangat penting. Adanya efek spasial merupakan hal yang lazim terjadi antara satu wilayah dengan wilayah yang lain. Pada beberapa kasus, variabel respon yang diamati memiliki keterkaitan dengan hasil pengamatan di wilayah yang berbeda, terutama wilayah yang berdekatan. Adanya hubungan spasial dalam variabel respon akan menyebabkan pendugaan menjadi tidak tepat karena asumsi keacakan galat dilanggar. Untuk mengatasi permasalahan tersebut diperlukan suatu model regresi yang memasukkan hubungan spasial antar wilayah ke dalam model, sehingga model yang digunakan adalah model regresi spasial (Arisanti, 2011).

Melihat dari sisi pengeluaran konsumsi masyarakat Sulawesi Selatan, mayoritas penduduk umur 7-12 tahun dari kalangan masyarakat miskin sampai kaya, sedang bersekolah. Namun beranjak pada kelompok usia selanjutnya (13-15 dan 16-18 tahun), penduduk pada kelompok pengeluaran terendah semakin menunjukkan bahwa banyak dari mereka mengalami putus sekolah (Badan Pusat Statistik, 2015). Beberapa peneliti sebelumnya telah melakukan penelitian menggunakan analisis spasial dalam menyelesaikan masalah di berbagai wilayah, diantaranya yaitu Fitroni \& Zain (2013), Arisanti (2011) dan Idris (2015). Berdasarkan beberapa penelitian sebelumnya, dengan memperhitungkan faktor lokasi penelitian ini mengkaji lebih lanjut mengenai model regresi spasial yang tepat untuk memodelkan angka putus sekolah di Provinsi Sulawesi Selatan.

\section{Analisis Regresi}

\section{Regresi Linier Berganda}

Regresi linier merupakan salah satu metode statistika yang membentuk sebuah model matematis antara variabel respon $(Y)$ dengan satu atau lebih variabel prediktor $(X)$. Bentuk umum model regresi linear berganda adalah (Tri, 2014):

$$
\begin{gathered}
\boldsymbol{y}=\boldsymbol{X} \boldsymbol{\beta}+\boldsymbol{\varepsilon} \\
\boldsymbol{\varepsilon} \sim \operatorname{IIDN}\left(\mathbf{0}, \sigma^{2} \boldsymbol{I}\right)
\end{gathered}
$$

\section{Model Umum Regresi Spasial}

Regresi spasial adalah salah satu metode statistik yang digunakan untuk mengetahui hubungan antara variabel respon dan variabel prediktor dengan mempertimbangkan keterkaitan lokasi. Bentuk model umumnya adalah (LeSage, 1999):

$$
\begin{gathered}
\boldsymbol{y}=\rho \boldsymbol{W} \boldsymbol{y}+\boldsymbol{X} \boldsymbol{\beta}+\boldsymbol{u} \\
\boldsymbol{u}=\lambda \boldsymbol{W} \boldsymbol{u}+\boldsymbol{\varepsilon} \\
\boldsymbol{\varepsilon} \sim N\left(\mathbf{0}, \sigma^{2} \boldsymbol{I}\right)
\end{gathered}
$$

Beberapa model yang bisa dibentuk dari model umum regresi spasial tersebut (Idris, 2015) yaitu:

1. Jika $\rho=0$ dan $\lambda=0$ maka persamaan menjadi model regresi klasik yaitu regresi Ordinary Least Square $(O L S)$.

$$
\boldsymbol{y}=\boldsymbol{X} \boldsymbol{\beta}+\boldsymbol{\varepsilon}
$$

2. Jika $\rho \neq 0$ dan $\lambda=0$ maka bentuk persamaan menjadi model Spatial Autoregresive (SAR). SAR terjadi akibat adanya dependensi nilai respon antar lokasi.

$$
y=\rho W_{1} y+X \beta+\varepsilon
$$


3. Jika $\rho=0$ dan $\lambda \neq 0$ maka bentuk persamaan menjadi model Spatial Error Model (SEM). SEM terjadi akibat adanya dependensi nilai error dilokasi yang lain.

$$
\begin{gathered}
y=X \beta+u \\
y=X \beta+\lambda W_{2} u+\varepsilon
\end{gathered}
$$

4. Jika $\rho \neq 0$ dan $\lambda \neq 0$ maka bentuk persamaan menjadi gabungan antara model SAR dan SEM atau biasa disebut Spatial Autoregressive Moving Average (SARMA).

$$
\boldsymbol{y}=\rho \boldsymbol{W}_{\mathbf{1}} \boldsymbol{y}+\boldsymbol{X} \boldsymbol{\beta}+\lambda \boldsymbol{W}_{\mathbf{2}} \boldsymbol{u}+\boldsymbol{\varepsilon}
$$

\section{Uji Signifikansi Parameter Regresi Spasial}

Salah satu prinsip dasar penduga maksimum likelihood adalah asymptotic normality, artinya semakin besar ukuran $n$ maka kurva akan semakin mendekati kurva sebaran normal. Pengujian parameter model regresi spasial secara parsial dilakukan untuk mengetahui parameter mana yang signifikan mempengaruhi variabel respon. Pengujian parameter regresi $(\beta)$ dan regresi spasial ( $\rho$ dan $\lambda$ ) secara parsial yaitu didasarkan pada nilai variansi error $\left(\sigma^{2}\right)$, sehingga statistik uji signifikan parameter yang digunakan adalah:

$$
Z_{\text {hitung }}=\frac{\widehat{\theta}}{\text { s.e }(\theta)}
$$

dengan hipotesis:

$H_{0}: \theta=0 \quad$ (parameter tidak signifikan)

$H_{1}: \theta \neq 0 \quad$ (parameter signifikan)

$\theta$ merupakan parameter $\beta, \rho$ dan $\lambda$. $H_{0}$ ditolak jika $Z_{\text {hitung }} \geq Z_{\alpha / 2}$ atau $p-$ value $<\alpha / 2$, artinya koefisien regresi signifikan sehingga layak digunakan pada model (Rati, 2013).

\section{Dependensi Spasial}

\section{Moran's I}

Moran's I paling sering digunakan untuk mengukur dependensi spasial global dan mengkuantifikasi kesamaan dari suatu variabel hasil antar wilayah yang didefinisikan sebagai spasial terkait. Permulaan dari keacakan spasial mengindetifikasikan pola spasial seperti berkelompok atau membentuk tren terhadap ruang (Idris, 2015). Perhitungan dependensi spasial menggunakan Moran's I dengan matriks pembobot W berdasarkan perkalian silang adalah:

$$
I=\frac{\sum_{i=1}^{n} \sum_{j=1}^{n} W_{i j}\left(x_{i}-\bar{x}\right)\left(x_{j}-\bar{x}\right)}{\sum_{i=1}^{n}\left(x_{i}-\bar{x}\right)^{2}}
$$

Hipotesis yang digunakan:

$H_{0}: I=0$ (tidak ada dependensi spasial)

$H_{1}: I \neq 0$ (ada dependensi spasial).

Statistik uji Moran's I adalah:

$$
Z(I)=\frac{I-E(I)}{\sqrt{\operatorname{Var}(I)}}
$$

$H_{0}$ ditolak jika $Z(I)>Z \alpha / 2$. Nilai yang dihasilkan dalam perhitungan Moran's I berkisaran antara -1 sampai 1. Nilai Moran's I bernilai nol mengindikasikan tidak berkelompok. Jika $I>I_{0}$ maka data memiliki autokorelasi positif yang berarti lokasi yang berdekatan mempunyai nilai yang mirip dan cenderung berkelompok, jika $I<I_{0}$ maka data memiliki autokorelasi negatif yang berarti lokasi yang berdekatan mempunyai nilai yang berbeda (Idris, 2015). 
Lagrange Multiplier (LM)

Statistik Lagrange Multiplier (LM) yang digunakan adalah:

$$
L M_{\text {lag }}=\frac{\left(\frac{\varepsilon^{T} W Y}{s^{2}}\right)}{\frac{\left.(\boldsymbol{W X} \boldsymbol{\beta})^{T} M(\boldsymbol{W} \boldsymbol{\beta})+T s^{2}\right)}{s^{2}}}
$$

Kriteria keputusan yaitu $H_{0}$ ditolak jika $L M_{\text {lag }}>\chi_{(\alpha, 1)}^{2}$ atau $p-$ value $<\alpha$ artinya model yang sesuai digunakan adalah SAR.

$$
L M_{\text {error }}=\frac{\left(\frac{\varepsilon^{T} W \varepsilon}{s^{2}}\right)^{2}}{T}
$$

Kriteria keputusan yaitu $H_{0}$ ditolak jika $L M_{\text {error }}>\chi_{(\alpha, 1)}^{2}$ atau $p-$ value $<\alpha$ artinya model yang sesuai digunakan adalah SEM.

\section{Matriks Pembobot Spasial}

Bentuk umum matriks spasial ( $\boldsymbol{W})$ adalah (Rati, 2013):

$$
\boldsymbol{W}=\left(\begin{array}{ccc}
W_{11} & \ldots & W_{1 n} \\
\vdots & \ddots & \vdots \\
W_{n 1} & \ldots & W_{n n}
\end{array}\right)
$$

Pembentukan matriks keterkaitan spasial yang sering disebut matrik $W$ dapat menggunakan berbagai teknik pembobotan. Matriks $W$ berdasarkan persentuhan batas wilayah (contiguity) menyatakan bahwa interaksi spasial terjadi antar wilayah yang bertetangga, yaitu interaksi yang memiliki persentuhan batas wilayah (common boundary). Sebuah matrik $W$ yang dibentuk adalah simetrik dan diagonal utama selalu bernilai nol. Secara umum terdapat berbagai tipe interaksi, yaitu rook contiguity, bishop contiguity, linear contiguity, dan queen contiguty.

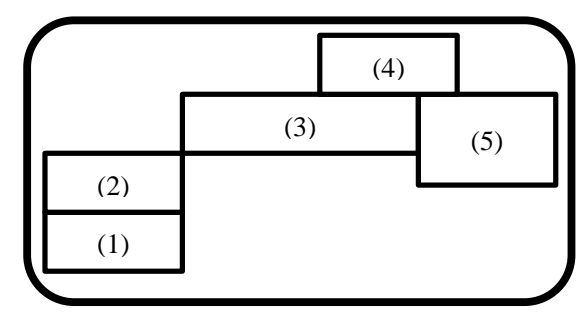

GAMBAR 1. Ilustrasi Pembobot Spasial

Matriks standardisasinya yaitu jumlah baris sama dengan satu, sehingga diperoleh matriks pembobot adalah:

$$
W_{\text {queen }}=\left[\begin{array}{ccccc}
0 & 1 & 0 & 0 & 0 \\
1 / 2 & 0 & 1 / 2 & 0 & 0 \\
0 & 1 / 3 & 0 & 1 / 3 & 1 / 3 \\
0 & 0 & 1 / 2 & 0 & 1 / 2 \\
0 & 0 & 1 / 2 & 1 / 2 & 0
\end{array}\right]
$$

\section{Putus Sekolah}

Putus sekolah adalah mereka yang pernah duduk pada salah satu tingkat pendidikan, akan tetapi pada saat survei berlangsung mereka tidak terdaftar pada salah satu pendidikan formal yang disebabkan oleh berbagai faktor. Angka putus sekolah mencerminkan presentasi anak-anak usia sekolah yang sudah tidak lagi bersekolah/tidak menamatkan jenjang pendidikan tertentu (Riyadi, dkk, 2015). 


\section{METODE PENELITIAN}

Data yang digunakan adalah data sekunder dari Survei Angkatan Kerja Nasional (Sakernas), Survei Sosial Ekonomi Nasional (Susenas) dan Sulawesi Selatan Dalam Angka (DDA) Provinsi Sulawesi Selatan Tahun 2015. Variabel respon yang digunakan pada penelitian ini yaitu jumlah angka putus sekolah tingkat SMP $\left(Y_{1}\right)$ dan jumlah angka putus sekolah tingkat SMA $\left(Y_{2}\right)$. Adapun variabel prediktor yang menjadi faktor-faktor dari angka putus sekolah adalah rasio siswa terhadap sekolah SMP $\left(X_{1.1}\right)$, rasio siswa terhadap sekolah SMA $\left(X_{1.2}\right)$, rasio siswa terhadap guru SMP $\left(X_{2.1}\right)$, rasio siswa terhadap guru SMA $\left(X_{2.2}\right)$, jumlah penduduk miskin $\left(X_{3}\right)$, tingkat kesempatan kerja $\left(X_{4}\right)$ dan kepadatan penduduk $\left(X_{5}\right)$.

Adapun langkah-langkah pada prosedur penelitian yaitu:

1. Melakukan eksplorasi data peta tematik untuk melihat gambaran pengaruh variabel respon di setiap wilayah.

2. Melakukan pemodelan regresi dengan metode Ordinary Least Square (OLS) yang meliputi estimasi parameter dan estimasi signifikansi model.

3. Menetapkan matriks pembobot spasial $(W)$ dengan metode queen contiguity.

4. Uji dependensi spasial dengan Moran's I.

5. Identifikasi keberadaan efek spasial dengan uji Lagrange Multiplier (LM).

6. Melakukan pemodelan spasial.

7. Interpretasi dan pemilihan model terbaik.

8. Kesimpulan.

\section{HASIL DAN PEMBAHASAN}

\section{Eksplorasi Data}

Peta tematik angka putus sekolah tingkat SMP dan SMA di Provinsi Sulawesi Selatan tahun 2015 ditunjukkan pada gambar 2 dan gambar 3. Pada peta tersebut, terlihat gradasi warna yang menunjukkan semakin pekat warna wilayahnya, maka semakin tinggi pula angka putus sekolah di wilayah tersebut.

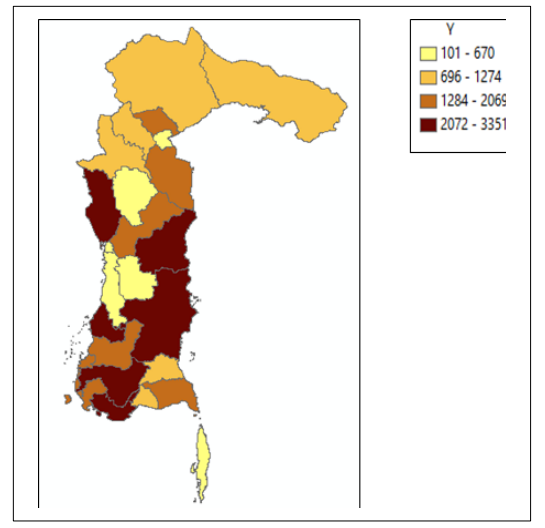

GAMBAR 2. Angka Putus Sekolah Tingkat SMP

Berdasarkan gambar 2, wilayah Provinsi Sulawesi Selatan dibagi menjadi 4 bagian. Wilayahwilayah tersebut disajikan dalam tabel 1 . 
TABEL 1. Jumlah Putus Sekolah Tingkat SMP Berdasarkan Wilayah

\begin{tabular}{ccccc} 
No. & $\begin{array}{c}\text { Wilayah 1 } \\
\mathbf{1 0 1 - 6 7 0}\end{array}$ & $\begin{array}{c}\text { Wilayah 2 } \\
\mathbf{6 9 6 - 1 2 7 4}\end{array}$ & $\begin{array}{c}\text { Wilayah 3 } \\
\mathbf{1 2 8 4 - 2 0 6 9}\end{array}$ & $\begin{array}{c}\text { Wilayah 4 } \\
\mathbf{2 0 7 2 - 3 3 5 1}\end{array}$ \\
\hline 1. & Selayar & Bantaeng & Bulukumba & Jeneponto \\
Gowa & Takalar & Gowakep \\
3. & Barru & Sinjai & Maros & Pangke \\
E. & Enrekang & Luwu Utara & Sidrap & Bone \\
5. & Soppeng & Luwu Timur & Luwu & Wajo \\
6. & Parepare & Tana Toraja & Makassar & Pinrang \\
\hline
\end{tabular}

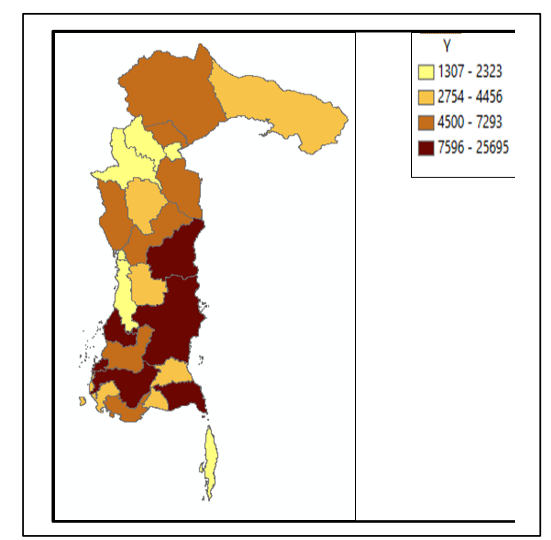

GAMBAR 3. Angka Putus sekolah Tingkat SMA

Berdasarkan gambar 3, wilayah Provinsi Sulawesi Selatan dibagi menjadi 4 bagian. Wilayahwilayah tersebut disajikan dalam tabel 2 .

TABEL 2. Jumlah Putus Sekolah Tingkat SMA Berdasarkan Wilayah

\begin{tabular}{ccccc} 
No. & Wilayah 1 & Wilayah 2 & Wilayah 3 & Wilayah 4 \\
& $\mathbf{1 3 0 7 - 2 3 2 3}$ & $\mathbf{2 7 5 4 - 4 4 5 6}$ & $\mathbf{4 5 0 0 - 7 2 9 3}$ & $\mathbf{7 5 9 6 - 2 5 6 9 5}$ \\
\hline 1. & Selayar & Bantaeng & Luwu Utara & Makassar \\
2. & Barru & Sinjai & Pinrang & Gowa \\
3. & Toraja Utara & Enrekang & Maros & Pangkep \\
4. & Tana Toraja & Luwu Timur & Sidrap & Bone \\
5. & Parepare & Soppeng & Luwu & Wajo \\
6. & Palopo & Takalar & Jeneponto & Bulukumba \\
\hline
\end{tabular}

\section{Estimasi Parameter}

Estimasi parameter $\beta$ model regresi liner berganda yaitu:

$$
\widehat{\boldsymbol{\beta}}=\left(\boldsymbol{X}^{T} \boldsymbol{X}\right)^{-1} \boldsymbol{X}^{T} \boldsymbol{Y}
$$

Estimasi parameter $\beta$ model SAR yaitu:

$$
\widehat{\boldsymbol{\beta}}=\left(\boldsymbol{X}^{T} \boldsymbol{X}\right)^{-1} \boldsymbol{X}^{T} \boldsymbol{y}-\left(\boldsymbol{X}^{T} \boldsymbol{X}\right)^{-1} \boldsymbol{X}^{T} \rho \boldsymbol{W} \boldsymbol{y}
$$

sedangkan estimasi parameter $\rho$ tidak didapatkan dengan memaksimumkan fungsi likelihood, sehingga untuk mendapatkan nilai paramater $\rho$ menggunakan software opengeoda.

Estimasi parameter $\beta$ model SEM yaitu: 


$$
\widehat{\boldsymbol{\beta}}=\left[(\boldsymbol{X}-\lambda \boldsymbol{W} \boldsymbol{X})^{T}(\boldsymbol{X}-\lambda \boldsymbol{W} \boldsymbol{X})\right]^{-1}\left[(\boldsymbol{X}-\lambda \boldsymbol{W} \boldsymbol{X})^{T}(\boldsymbol{y}-\lambda \boldsymbol{W} \boldsymbol{y})\right]
$$

sedangkan estimasi parameter $\lambda$ tidak didapatkan dengan memaksimumkan fungsi likelihood, sehingga untuk mendapatkan nilai paramater $\lambda$ menggunakan software opengeoda.

\section{Model Regresi Klasik}

Pemodelan regresi klasik digunakan untuk mengetahui hubungan variabel-variabel prediktor terhadap angka putus sekolah. Tabel 3 dan 4 menyajikan hasil pengujian model regresi klasik untuk angka putus sekolah tingkat SMP dan SMA di Provinsi Sulawesi Selatan tahun 2015.

TABEL 3. Estimasi Parameter pada Model Regresi Klasik Tingkat SMP

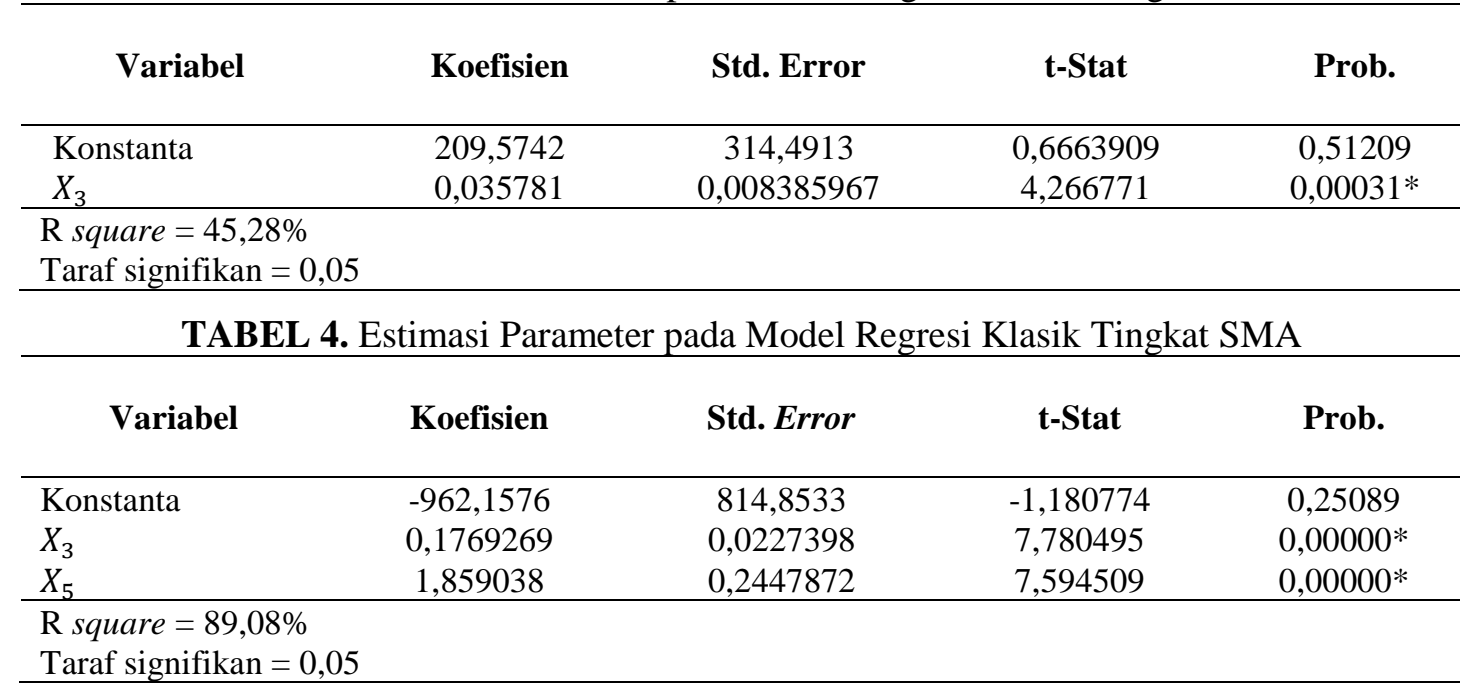

\section{Dependensi Spasial}

Pengujian yang dilakukan untuk mengetahui adanya dependensi spasial di dalam suatu model yaitu dengan menggunakan statistik uji Moran's I dan Langrange Multiplier (LM). Hasil pengujiannya disajikan pada tabel 5, 6 dan 7 .

\begin{tabular}{ccc}
\multicolumn{3}{c}{ TABEL 5. Hasil Uji Moran's $I$} \\
\hline Variabel & Moran's I & $\boldsymbol{Z}(\boldsymbol{I})$ \\
\hline$Y_{1}$ & 0,1611 & 1,4914 \\
$Y_{2}$ & 0,1000 & 1,0460 \\
$X_{1.1}$ & $-0,0567$ & $-0,0962$ \\
$X_{1.2}$ & 0,2224 & 1,9382 \\
$X_{2.1}$ & 0,0604 & 0,7574 \\
$X_{2.2}$ & 0,1177 & 1,1750 \\
$X_{3}$ & 0,0878 & 0,9571 \\
$X_{4}$ & 0,0843 & 0,9316 \\
$X_{5}$ & $-0,0111$ & 0,2362 \\
\hline$Z_{0,025}=1,96$ & & \\
$I_{0}=-0,0435$ & \\
\hline
\end{tabular}


Berdasarkan tabel 5 dan nilai $I_{0}$ terlihat bahwa secara keseluruhan nilai Moran's I bernilai lebih besar dari $I_{0}$ yang artinya secara keseluruhan variabel respon maupun prediktor memiliki autokorelasi positif yang berarti wilayah yang berdekatan mempunyai nilai yang mirip dan cenderung berkelompok (cluster). Kecuali pada variabel rasio siswa terhadapat sekolah SMP $\left(X_{1.1}\right)$ Moran's I bernilai lebih kecil dari $I_{o}$ dan bernilai negatif, ini mengidentifikasikan dependensi spasial negatif yang berarti lokasi yang berdekatan mempunyai nilai yang berbeda.

TABEL 6. Hasil Uji Lagrange Multiplier untuk Tingkat SMP

\begin{tabular}{lcc}
\hline \multicolumn{1}{c}{ Uji Spatial Dependence } & Nilai & p-value \\
\hline Moran's I & $-0,0427$ & 0,96598 \\
Lagrange Multiplier (lag) & 0,5719 & 0,44950 \\
Lagrange Multiplier (error) & 0,2141 & 0,64354 \\
Lagrange Multiplier (SARMA) & 2,9888 & 0,22439 \\
\hline
\end{tabular}

Berdasarkan tabel 6 diketahui bahwa nilai $p$-value Moran's tidak signifikan pada $\alpha=0,05$ yang berarti bahwa tidak terdapat dependensi spasial untuk kasus putus sekolah tingkat SMP. Dan pada uji Lagrange Multiplier tidak satupun nilai $p$-value baik pada lag maupun error yang signifikan yang artinya tidak ada dependensi spasial baik lag maupun error.

TABEL 7. Hasil Uji Lagrange Multiplier untuk Tingkat SMA

\begin{tabular}{lcc}
\hline \multicolumn{1}{c}{ Uji Spatial Dependence } & Nilai & p-value \\
\hline Moran's I & 2,7055 & $0,00682^{*}$ \\
Lagrange Multiplier (lag) & 1,4039 & 0,23607 \\
Lagrange Multiplier (error) & 3,8932 & $0,04848^{*}$ \\
Lagrange Multiplier (SARMA) & 4,1426 & 0,12602 \\
\hline
\end{tabular}

Berdasarkan tabel 7 diketahui bahwa nilai $p$-value Moran's signifikan padan $\alpha=0,05$ yang berarti bahwa terdapat dependensi spasial untuk kasus putus sekolah tingkat SMA. Dan pada uji Lagrange Multiplier terlihat nilai $p$ - value dari Lagrange Multiplier (error) sebesar 0,04848 yang lebih kecil dari $\alpha=0,05$, sehingga model akan dilanjutkan ke Spatial Error Model (SEM). Sedangkan nilai $p$ - value dari Lagrange Multiplier (lag) sebesar 0,23607 yang lebih besar dari $\alpha=0,05$, sehingga model tidak perlu dilanjutkan pada model Spatial Autoregressive (SAR).

\section{Spatial Error Model (SEM)}

Hasil estimasi parameter pada model SEM disajikan pada tabel 8.

TABEL 8. Estimasi Parameter pada Model SEM

\begin{tabular}{lllll}
\hline Variabel & Koefisien & Std. Error & $\boldsymbol{z}$-value & Prob. \\
& & & & \\
\hline Konstanta & $-1003,144$ & 777,9677 & $-1,289442$ & 0,19724 \\
$X_{3}$ & 0,1774124 & 0,02073041 & 8,558074 & $0,0000^{*}$ \\
$X_{5}$ & 1,831541 & 0,218371 & 8,387291 & $0,0000^{*}$ \\
$\lambda$ & 0,2711281 & 0,2471475 & 1,097029 & 0,27263 \\
\hline R square $=89,78 \%$ & & & \\
\multicolumn{2}{l}{ Taraf signifikan $=0,05$} & & & \\
\hline
\end{tabular}


Berdasarkan tabel 8 diperoleh model persamaan SEM yaitu:

$$
\hat{y}_{i}=-1003,144+0,1774124 X_{3}+1,831541 X_{5}+u_{i}
$$

dimana $u_{i}=0,2711281 \sum_{j=1, i \neq j}^{24} W_{i j} u_{j}+\varepsilon_{i}$.

Model SEM dapat diinterpretasikan bahwa apabila faktor lain dianggap konstan, maka ketika jumlah penduduk miskin $\left(X_{3}\right)$ naik satu satuan maka prediksi nilai angka putus sekolah akan naik sebesar 0,1774124 dan apabila kepadatan penduduk $\left(X_{5}\right)$ naik satu satuan maka prediksi nilai angka putus sekolah akan naik sebesar 1,831541. Adapun error spasial antar kabupaten/kota saling berkorelasi sebesar 0,2711281, yang artinya interaksi spasial antar 24 kabupaten/kota di Provinsi Sulawesi Selatan yang memiliki persinggungan area adalah sebesar 0,2711281.

\section{Perbandingan Model Regresi Klasik dan Model Regresi Spasial}

Pada pemodelan regresi, untuk memperoleh model terbaik maka dilakukan dengan membandingkan hasil persamaan regresi yang diperoleh dari kedua metode yang digunakan. Koefisien determinan $R^{2}$ dan metode AIC dapat digunakan untuk menentukan model terbaik. Semakin nilai $R^{2}$ mendekati satu, maka semakin tinggi pengaruh variabel prediktor terhadap variabel respon, yang berarti semakin baik kecocokan model dengan data. Menurut metode AIC, model regresi terbaik adalah model regresi yang mempunyai nilai AIC terkecil. Perbandingan nilai $R^{2}$ dan AIC dapat dilihat pada tabel 9 .

TABEL 9. Nilai $R^{2}$ dan AIC Model OLS dan SEM

\begin{tabular}{lcc} 
Model & $\boldsymbol{R}^{\mathbf{2}}$ & AIC \\
\hline OLS & $89,08 \%$ & 431,727 \\
SEM & $89,78 \%$ & 430,604 \\
\hline
\end{tabular}

Berdasarkan tabel 9, secara keseluruhan nilai $R^{2}$ yang dihasilkan model SEM lebih besar daripada model OLS. Selain itu, nilai AIC yang dihasilkan pada model SEM juga lebih kecil dibandingkan model OLS. Sehingga dapat disimpulkan bahwa model SEM lebih baik digunakan dalam memodelkan angka putus sekolah di Provinsi Sulawesi Selatan Tahun 2015.

\section{KESIMPULAN}

Berdasarkan hasil dan pembahasan mengenai aplikasi regresi spasial untuk pemodelan angka putus sekolah di Provinsi Sulawesi Selatan, maka diperoleh kesimpulan yaitu:

1. Angka putus sekolah untuk tingkat SMP tidak memiliki dependensi spasial baik lag maupun error. Maka hal ini menandakan bahwa pada tingkat SMP di setiap kabupaten/kota di Provinsi Sulawesi Selatan tidak memiliki ketergantungan antar daerah. Adapun hasil analisis model regresi klasiknya diperoleh bahwa faktor-faktor yang signifikan berpengaruh terhadap angka putus sekolah untuk tingkat SMP di Provinsi Sulawesi Selatan adalah jumlah penduduk miskin.

2. Angka putus sekolah untuk tingkat SMA memiliki dependensi spasial dalam error, sehingga model regresi spasial yang digunakan adalah model SEM. Berdasarkan hasil analisis model SEM diperoleh bahwa faktor-faktor yang signifikan berpengaruh terhadap angka putus sekolah untuk tingkat SMA di Provinsi Sulawesi Selatan adalah jumlah penduduk miskin dan kepadatan penduduk. 


\section{DAFTAR PUSTAKA}

Ruliana. (2015). Pemodelan Generalized Poisson Regression (GPR) untuk Mengatasi Pelanggaran Equidispersi pada Regresi Poisson Kasus Campuk di Kota Semarang (Skripsi). Universitas Negeri Semarang, Semarang.

Drapper, N. R., dan Smith, H. (1992). Analisis Regresi Terapan (Terjemahan B.Sumantri). dalam Edisi Kedua. Jakarta: PT. Gramedia Pustaka Utama

Anselin, L. (1988). Spatial Econometrics: Methods and Models. Dordrecht: Kluwer Academic Publishers.

Arisanti, R.. (2011) Model Regresi Spasial untuk Deteksi Faktor-Faktor Kemiskinan di Provinsi Jawa Timur (Skripsi). Institut Pertanian Bogor, Bogor.

Badan Pusat Statistik. (2015). Statistika Daerah Provinsi Sulawesi Selatan 2015. Makassar: Badan Pusat Statistika Provinsi Sulawesi Selatan.

Fitroni, B.N., dan Zain, I. (2013). Pemodelan Angka Putus Sekolah Usia Wajib Belajar Menggunakan Metode Regresi Spasial di Jawa Timur. Jurnal Sains dan Seni Pomits, 2(2). 171-176.

Idris, Z.F. (2015). Pemodelan Kriminalitas dengan Pendekatan Regresi Spasial di Provinsi Sulawesi Selatan (Skripsi). Universitas Negeri Makassar, Makassar.

Tri, A.I. (2014). Aplikasi Regresi Spasial untuk Pemodelan Angka Harapan Hidup (AHH) di Provinsi Jawa Tengah (Skripsi). Universitas Negeri Yogyakarta, Yogyakarta.

LeSage, J.P. (1999). The Theory and Practice of Spatial Econometrics. United States: Department of Economics University of Toledo.

Rati, M. (2013). Model Regresi Spasial untuk Anak Tidak Bersekolah Usia Kurang 15 Tahun di Kota Medan (Skripsi). Universitas Sumatra Utara, Medan.

Riyadi, Hartini, S,. Rudyansah, Z., Anam, C., Hastuti, A., Setiyawati, N., et al. (2015). Indikator Kesehatan Rakyat 2015. Jakarta: Badan Pusat Statistik. 